\title{
Characteristics Influencing Digital Technology Choice in Digitalization Projects of Energy Industry
}

\author{
Chankook PARK ${ }^{1}$, Minkyu KIM ${ }^{2 *}$ \\ ${ }^{1,2}$ Korea Energy Economics Institute, Ulsan, South Korea
}

\begin{abstract}
Digitalization projects are actively underway in the energy industry, such as the power industry and oil and gas industry. However, there has been no in-depth and quantitative analysis of the relationships between the participants, industry, and technology of digital projects. Therefore, this study focused on which technologies are invested according to key characteristics such as the types of participants and industries driving digitalization projects. This study also examined whether there are differences in technology choices depending on the degree of clean energy exposure. Based on statistics from Bloomberg New Energy Finance (BNEF), a total of 711 projects were analysed using multinomial logistic regression (MNLR). As a result, the proportion of Analytics software was generally higher in the whole industry, and the energy industry was more likely to invest in Analytics software than in other industries. Comparing the power, oil and gas sectors, there was a high probability of investment in Internet of Things (IoT) in the power sector and Automation in the oil and gas sector. In the type of cooperation between energy companies and industrial companies, the probability of investing in Analytics software was significantly higher. In the case of cooperation between energy companies and information and communications technology (ICT) companies, in the oil and gas sector, Analytics software and Cloud/Data accounted for a large proportion. This study provides insight into the effect of characteristics of energy digitalization projects on the technology choice.
\end{abstract}

Keywords - Digital technology choice; digitalization projects; energy digitalization; oil and gas industry; power industry

\section{INTRODUCTION}

New value is being created as all processes, including energy production, delivery, and consumption, are digitalized and data from each process is collected and analysed in real time through information and communications technology (ICT) [1]. Digitalization has been defined as the restructuring process of transforming various parts of life into digital. Through digitalization, people are connected to each other, things are connected to each other, so human life is more closely connected than before, and there is an opportunity to create new values in that connection [2].

In the energy industry, power, oil and gas industries are representative of the areas where digitalization is actively carried out. In the power industry, smart grids are a prime example of digitalization. Smart grids are defined as a digitalized power network that encompasses the production, transmission, distribution, and consumption of electricity [3]. With the development of digital technology, smart grids smoothly connect renewable energy with intermittent output to the power system and analyse power production and consumption data

* Corresponding author.

E-mail address:minkyu247@keei.re.kr 
in an integrated power grid to balance power production and consumption. As a result, smart grids improve the stability of energy supply and the efficiency of management [4].

The oil and gas industry are also steadily digitalizing. The most prominent business model change in the oil and gas industry is the resource development service sector. Equipment manufacturers maintain and repair their equipment that combines machine learning technology and provide support services such as data monitoring to help customers optimize equipment utilization [5]. In the upper part of the oil and gas industry, facilities that mine resources are usually located in remote areas, so if they are able to monitor and control facilities remotely, they will greatly contribute to improving productivity. In the midstream sector, many equipment such as corrosive-preventing electrical sensors are currently installed along the pipeline, and sensors that can easily check asset status are being used. The downstream sector is pursuing innovation in the crude oil refining process, especially by utilizing big data and Artificial Intelligence (AI) technologies in the crude oil refining industry [6]-[8].

Digital technologies such as AI and IoT also contribute to enhancing the sustainability of the energy industry. The digitalization of the energy industry plays a role in enabling efficient management of scattered low carbon distributed power generation and enhancing the utilization of energy storage devices. In addition, in terms of energy demand, the digitalization of the energy industry can reduce unnecessary energy consumption and enable efficient use of energy. Also, it provides the basis for an information system that can monitor and respond to carbon emissions of the energy sector [9]-[11].

These active digitalization projects in the energy industry, including the power, oil and gas industries, are investing in digital technologies such as AI, Internet of Things (IoT), Cloud, etc. according to the characteristic of the projects [1], [12], [13]. The technologies selected in digitalization projects are essentially dependent on the benefits that projects want to gain from their investments. Understanding the functions of each technology and the goals of the projects at the same time can partially predict the direction of technology choice for each project. However, these exploratory efforts keep us at a level that merely understands the benefits of digital technology. If there is information about the types of participants driving digitalization projects and related industries, it can get insights on what types of technologies companies invest mainly and what technologies they actively utilize depending on the type of industry. Until now, there has been no in-depth analysis of how digital technology investment, project participant, and the industry in which projects are promoted have been linked due to the lack of relevant data.

In this study, based on statistics from Bloomberg New Energy Finance (BNEF), we analyse how the types of technologies invested in digitalization projects in the energy industry differ depending on the project participant and the industry in which the project is driven. BNEF provides statistics on recent digitalization projects in various industries through media and press releases. This dataset contains information on the participant of each project, related industries, etc. In this study, the analysis of this dataset aims to derive the probability of digital technology choice by project participant and industry and provide insight into the trend of digitalization in the energy industry.

\section{Literature REVIEW}

Digitalization projects invest in a variety of digital technologies, depending on the characteristics of each project. This study aims to statistically analyse the project characteristics. The characteristics that make up a project can include various factors such as the type of participants, the industrial sector in which the project is promoted, the region, the 
budget, etc. However, quantitative studies of the characteristics of digitalization projects are uncommon, especially in the energy sector. This is because there has been no reliable data on the properties of digitalization projects. Thus, this literature review section focuses on major related studies that lack direct relevance to this study, but have influenced variable selection. Research on digitalization projects generally deals with the effects of digital technologies, trends in digitalization projects according to industry, characteristics of project participants, and cooperation structures.

The advent of new digital technologies is effectively changing innovation and entrepreneurship [14]. In particular, digital technology development has the potential to significantly change energy supply, transaction and consumption [15]. In the energy sector, digital technologies increase the efficiency, stability, and safety of energy supply and reduce energy consumption and costs by collecting and analysing large amounts of data generated during energy supply and consumption [1], [13]. Mainly utilized digital technologies include IoT to generate and deliver data that is needed from remote, AI, blockchain, analytic software like digital twin, cloud to store and customize collected data, network technology to enable massive data transfer and remote control, and automation technology to improve the efficiency and safety of work [12], [13], [16], [17].

The choice of technologies invested in digitalization projects depends on who the project's drivers are and what industry the project is driven by. Digitalization projects involve a variety of participants, resulting in convergence between heterogeneous industries [1], [18], [19]. Existing entities cannot simply rely on their own traditional assets and structures, need to adapt and become proficient in innovative development, seek new types of partnerships to acquire the knowledge and share resources needed in new environments [20]. The exchange and acquisition of new knowledge required for digitalization is a key driver for facilitating cooperation among various companies [21]-[23]. In the energy sector, various types of operators are also participating in the digitalization process. Energy companies, as well as telecommunications companies that can provide digital solutions while having telecommunications networks, high-tech software-based software companies like Google and Apple, industrial companies that have traditionally bonded with energy companies to provide devices and solutions, chemical-based companies and automobile companies that promote the utilization of energy storage resources, consumer sector companies that are entering the energy consumption efficiency of ordinary customers are entering the energy industry through digitalization projects [1].

Meanwhile, in the energy sector, digitalization projects contribute to the efficiency and safety of traditional energy asset management such as thermal power plants, nuclear power plants, and oil and gas facilities, but many are linked to the promotion of distributed resources such as renewable energy resources, storage and demand management resources [24]. Since distributed resources are small but scattered in many places, the ability to use digital technologies to optimally manage and control them is needed to effectively utilize distributed resources. As distributed resources are rapidly increasing in the future, it is expected that digitalization projects in the energy sector will grow together [25]. In addition, it is inferred that the demand for digitalization will increase as the proportion of clean energy-related projects increases in the business area of companies. 


\section{Data, VARiables, AND Methods}

\subsection{Data Collection}

This study examines the characteristics of digital technology investments based on information on digital projects in various industries including the energy industry. First of all, information on digital technology investment projects of industries should be obtained. In this study, the dataset of BNEF's Digitalization Leaderboard is used. BNEF is collecting digitalization project and partnership announcements through publicly available press releases and news. The dataset provided by BNEF contains information on a total of 1008 digitalization projects from 2007 to October 2020. However, since the data captured prior to 2018 is incomplete due to limited coverage, this study utilizes information on digitalization projects from 2018 to October 2020. In that period, 893 project information is included.

BNEF's dataset contains information on the digital technologies the projects are focused on, the announcement dates of the projects, the companies and partners of the project, and the industries in which the project is being performed. In this study, while utilizing BNEF's digitalization project dataset, additionally, information on exposure to clean energy of companies leading the projects is also used. The information provided by BNEF shows how actively companies leading the projects are doing in clean energy areas such as renewable energy, energy smart technologies, carbon capture and storage (CCS), and carbon markets based on their financial information. However, when the dataset of BNEF's Digitalization Leaderboard and the exposure to clean energy information of the companies participating in the projects are integrated, the total number of projects is reduced to 711. It is because data related to exposure to clean energy of companies that have promoted the projects are partially missing. Therefore, in this study, the information of the 711 projects, which is combined with the information of the digitalization project and the clean energy exposure information of companies, is utilized.

\subsection{Dependent Variable}

The focus of this study is what technologies are invested in depending on the characteristics of digitalization projects. Therefore, digital technologies invested in projects were set as dependent variables. The digital technologies invested in BNEF's dataset are largely classified into six types which are Analytics software, Communications, Cloud / Data, Automation, Connectivity, and IoT hardware. And again, each sector is subdivided into 2 to 5 lower-level technologies. The Analytics software includes AI, blockchain, digital twin, augment reality, virtual reality, and predictive maintenance technologies. The Communications include cellular networks, narrow-band networks, and satellite networks. The Cloud / Data includes cloud computing, edge computing, fog computing, data centre, and cybersecurity technologies, and the Automation technology includes robotics and drones. The Connectivity includes new sensor deployment and connected sensors, and the IoT hardware includes electronic chips. Since the concept of IoT includes sensors, it was determined that the Connectivity and the IoT hardware could be integrated into IoT. In this study, in order to increase the independence between technology options, the types of technologies invested in the project are set to five types which are Analytics software, Communications, Cloud / Data, Automation, and IoT.

\subsection{Independent Variables}

Depending on who the digitalization projects are being driven by, the main digital technologies of those projects can be different. Since this study focuses on digitalization 
projects in the energy sector, digitalization projects are divided into projects where energy sector companies participate and projects that do not. Projects in which energy companies participate are further subdivided into types in which only energy companies participate, energy companies and ICT companies participate, energy companies and industrial companies participate, and energy companies and other companies participate. In other words, the entities participating in the digitalization project are divided into energy companies, energy-ICT sector companies, energy-industrial sector companies, energy-other sector companies, and the remaining sectors without participation of energy sector companies. The reasons for looking at ICT and Industrial companies separately are as follows. As ICT companies are leading the way in digitalization, they are also becoming a major target of cooperation in digitalizing the energy industry. Industrial companies, such as GE, ABB, and Siemens, provide major components, equipment, and control technologies in the energy industry, and have long maintained partnerships with energy companies. Therefore, they are recognized as a major partner of energy companies in digitalization projects as well. The ICT sector includes IT infrastructure, digital software, and telecommunications. Other sectors excluding ICT and Industrial include construction, engineering, consumer, logistics, and manufacturing.

The industry in which the projects are being pursued is also a key issue. In this study, industries in which digitalization projects are pursued are classified into power industry, oil and gas industry, and other industries. Even if the companies participating in the projects are not energy companies, they can pursue digitalization projects in the energy sector such as power sector, or oil and gas sector. The other industry sector refers to the remaining industries excluding the power, oil and gas industries. This study tries to examine which technologyoriented digitalization projects are promoted by industry.

Digitalization is likely to be promoted more actively by companies with high levels of the clean energy exposure than those with low levels. There have been few studies on which digital technology-oriented projects will be pursued according to the degree of the clean energy exposure. Information on the clean energy exposure provided by BNEF refers to an estimate of the percent of an organization's value that is attributable to its activities in renewable energy, energy smart technologies, CCS, and carbon markets. BNEF assesses an organization's sectors and sub-activities within these clean energy areas, and then calculate an estimate using reported segmented revenues. BNEF uses metrics such as Earnings Before Interest, Taxes, Depreciation and Amortization (EBITDA). The level of the clean energy exposure is divided into four stages which are Main driver, Considerable, Moderate, and Minor. The Main driver level means 50 to $100 \%$ of the organization's value is estimated to derive from the clean energy activities. The Considerable level means $25 \sim 49 \%$, the moderate level means $10 \sim 24 \%$, and the minor level means less than $10 \%$.

\subsection{Methods}

This study presumes that a project chooses the right digital technology for that project. Therefore, we use multinomial logistic regression (MNLR) to see what properties of the project the digital technology is selected for. MNLR is used to model more than two categories of the dependent variable, where the log odds of the outcomes are modelled as a linear combination of the predictor variables [26]. MNLR is an extension version of binary logistic regression. MNLR uses maximum likelihood estimation to evaluate the probability of categorical membership like binary logistic regression. MNLR assumes the independence of irrelevant alternatives [27].

MNLR is a logistic regression model that estimates several binary logistic regression models simultaneously. In the case of an unranked categorical dependent variable consisting 
of $k$ categories, $k-1$ binary logistic regression models that predict the probability of occurrence of other categories compared to the reference level category are constructed. Then, by estimating those models simultaneously, we can get probability values $(P(1), P(2), \ldots P(k))$ for $k$ categories [28].

$$
\begin{aligned}
& \log \left(\frac{P(Y=1 \mid x)}{P(Y=K \mid x)}\right)=\beta_{0,1 \mid K}+\beta_{1,|| K} x \\
& \quad \ldots \\
& \log \left(\frac{P(Y=K-1 \mid x)}{P(Y=K \mid x)}\right)=\beta_{K-1, K-1 \mid K}+\beta_{K-1, K-1 \mid K} x,
\end{aligned}
$$

where $\beta_{1}$ indicates the change in the $\log$ odds of $Y=1$ relative to $Y=K$ associated with a one unit change in $X$. If the exponentiated coefficient $\exp \left(\beta_{1}\right)$ is the amount by which the relative risk $P(Y=1) / P(Y=K)$ is multiplied when variable $X$ is increased by one unit [29].

This study has four equations because it is set that projects choose one of five types of digital technologies. Each equation models the odds of a choice relative to a baseline. This study set the Communications as the baseline among digital technologies. In independent variables of Industry and Participants, which are dummy variables, we set ETC as the baseline. For the analysis of MNLR, this study used the $R$ package net.

\section{Results}

Table 1 shows the descriptive statistics of the dependent and independent variables. Digital technology, which is a dependent variable, has a total of five types. In total 711 samples, Analytics software shows 304 and Cloud / Data shows 194. Among the independent variables, the variable Industry has a total of 3 types, with 181 in the power industry, 119 in the oil and gas industry, and 411 in the remaining industries. There are 5 types of project participants, with 460 projects without energy companies being the most, followed by energy and ICT cooperation with 105 types. Clean energy exposure has scores from 1 to 4 , with an average of 1.37 .

\begin{tabular}{|c|c|c|c|c|c|c|c|c|}
\hline & Variables & Description & Sumn & nary & & & & \\
\hline \multirow[t]{2}{*}{ Dependent } & \multirow[t]{2}{*}{ Technology } & \multirow{2}{*}{$\begin{array}{l}\text { Digital technology for } \\
\text { investment by project }\end{array}$} & IoT & $\begin{array}{l}\text { Analytics } \\
\text { software }\end{array}$ & Automation & $\begin{array}{l}\text { Cloud/ } \\
\text { Data }\end{array}$ & $\begin{array}{l}\text { Commun- } \\
\text { ications }\end{array}$ & Total \\
\hline & & & 86 & 304 & 48 & 194 & 79 & 711 \\
\hline \multirow{6}{*}{ Independent } & \multirow{2}{*}{ Industry } & \multirow{2}{*}{$\begin{array}{l}\text { Industry in which the project } \\
\text { is being promoted }\end{array}$} & \multicolumn{2}{|c|}{ Power } & Dil and Gas & ETC & \multicolumn{2}{|r|}{ Total } \\
\hline & & & \multicolumn{2}{|c|}{181} & 119 & 411 & & 711 \\
\hline & \multirow{2}{*}{ Participants } & \multirow{2}{*}{$\begin{array}{l}\text { Types of participants by } \\
\text { project }\end{array}$} & E_IC & TT $\underset{\text { strial }}{\text { E_Indu- }}$ & E_ETC & Energy & ETC & Total \\
\hline & & & 105 & 34 & 51 & 61 & 460 & 711 \\
\hline & \multirow{2}{*}{$\begin{array}{l}\text { Clean energy } \\
\text { exposure }\end{array}$} & \multirow{2}{*}{$\begin{array}{l}\text { Degree of the clean energy } \\
\text { exposure of a company } \\
\text { leading the project }\end{array}$} & \multicolumn{2}{|c|}{ Min } & Median & \multicolumn{2}{|c|}{ Mean } & Max \\
\hline & & & \multicolumn{2}{|c|}{1.0} & 1.0 & \multicolumn{2}{|l|}{1.37} & 4.0 \\
\hline
\end{tabular}

TABle 1. Descriptive Statistics of VARIABLES

Note: ETC stands for et cetera, that is, the rest, E_ICT stands for Energy and ICT, E_Industrial stands for Energy and Industrial, and E_ETC stands for Energy and the rest. The higher the value of clean energy exposure, the cleaner energyrelated activities are. 
Table 2 shows the analysis results of the research model. The stepwise variable selection method was used, and the likelihood-ratio test was used to assess the goodness of fit of statistical models. As a result of the likelihood-ratio test, at the significance level of 0.05 , the model presented in Table 2 was found to be the most suitable. However, since this model includes moderating effects, the main effects of variables other than Clean Energy Exposure cannot be interpreted immediately, and there is a hassle to consider the interaction effects together. For example, the interaction effect of Oil and Gas and E_Industrial on the dependent variable is as follows. While controlling the Clean Energy Exposure effect, the probability of choosing Cloud/Data over Communications in the oil and gas industry is decreased by $88.6 \%$ $\left(0.114 \approx \mathrm{e}^{12.837-15.012}=\mathrm{e}^{-2.175}\right)$ when the type of project participants is E_Industrial, a form in which energy and industrial companies cooperate, compared to ETC that does not include energy companies. The effect of Clean Energy Exposure can be interpreted more easily. When controlling the effect of the industry and the type of participants, the higher the degree of Clean Energy Exposure, the higher the probability of adopting other technologies than Communications.

TABLE 2. RESEARCH Model AND ANALysis RESUlt

\begin{tabular}{|c|c|c|c|c|}
\hline Terms & $\begin{array}{l}\text { Analytics } \\
\text { software }\end{array}$ & Automation & Cloud/Data & IoT \\
\hline (Intercept) & $0.060(0.348)$ & $-1.509 * *(0.478)$ & $-0.048(0.359)$ & $-1.301 * *(0.400)$ \\
\hline Oil and Gas & $12.686^{* * *}(0.532)$ & $-3.122 * * *(0.471)$ & $12.837 * * *(0.533)$ & $11.822 * * *(0.756)$ \\
\hline Power & $0.658(0.520)$ & $-0.314(0.877)$ & $0.190(0.552)$ & $-0.080(0.674)$ \\
\hline E_ETC & $24.619 * * *(0.599)$ & $7.494 * * *(0.334)$ & $26.159 * * *(0.599)$ & $2.454 * * *(0.376)$ \\
\hline E_ICT & $13.207 * * *(0.586)$ & $-6.125 * * *(0.544)$ & $11.732 * * *(0.781)$ & $13.405 * * *(0.671)$ \\
\hline E_Industrial & $-8.282 * * *(0.614)$ & $-17.905 * * *(0.000)$ & $22.842 * * *(0.693)$ & $-1.701 *(0.780)$ \\
\hline Energy & $24.510 * * *(0.731)$ & $10.309 * * *(0.342)$ & $3.399 * * *(0.254)$ & $25.625 * * *(0.732)$ \\
\hline Clean Energy Exposure & $0.605 *(0.268)$ & $0.590^{+}(0.345)$ & $0.579 *(0.275)$ & $0.851 * *(0.289)$ \\
\hline Oil and Gas: E_ETC & $-9.500 * * *(0.802)$ & $23.838 * * *(0.322)$ & $-13.621 * * *(0.964)$ & $12.758 * * *(0.643)$ \\
\hline Power: E_ETC & $-1.062(0.675)$ & $17.016^{* * *}(0.451)$ & $-3.086 * * *(0.714)$ & $21.170 * * *(0.505)$ \\
\hline Oil and Gas: E_ICT & $-24.819 * * *(0.757)$ & $8.769 * * *(0.591)$ & $-23.931 * * *(0.928)$ & $-25.082 * * *(1.065)$ \\
\hline Power: E_ICT & $-13.546 * * *(0.686)$ & $5.866 * * *(0.745)$ & $-12.146^{* * *}(0.890)$ & $-13.204 * * *(0.874)$ \\
\hline Oil and Gas: E_Industrial & $18.590 * * *(0.483)$ & $-4.474 * * *(0.000)$ & $-15.012 * * *(0.622)$ & $11.253 * * *(0.731)$ \\
\hline Power: E_Industrial & $9.226 * * *(0.633)$ & $-11.490 * * *(0.000)$ & $-23.287 * * *(0.779)$ & $1.526(0.937)$ \\
\hline Oil and Gas: Energy & $-8.620 * * *(0.916)$ & $22.201 * * *(0.290)$ & $11.857 * * *(0.408)$ & $-9.658 * * *(1.075)$ \\
\hline Power: Energy & $0.539(0.797)$ & $15.426 * * *(0.480)$ & $21.770 * * *(0.348)$ & $0.727(0.839)$ \\
\hline Log Likelihood $x^{2}(\mathrm{df})$ & \multicolumn{4}{|c|}{$128.415 * * *(64)$} \\
\hline McFadden's $R^{2}$ & \multicolumn{4}{|c|}{0.065} \\
\hline AIC & \multicolumn{4}{|c|}{1989.356} \\
\hline BIC & \multicolumn{4}{|c|}{2281.623} \\
\hline
\end{tabular}

Note: ${ }^{+} p<0.10,{ }^{*} p<0.05,{ }^{* *} p<0.01,{ }^{* * *} p<0.001, N=711$. The number in parentheses is a standard error.

It is easier to understand if the research results are expressed in figures. As shown in Fig. 1, based on the above analysis results, the probability value of technology choice of each project has been predicted, and the probability value for each major attribute of the projects has been derived.

The upper figure in Fig. 1 shows the probability value of technology choice by industry. Overall, Analytics software is highly likely to be selected in all industries, followed by 
Cloud/Data. The energy industry has a higher probability of investing in Analytics software than other industries. The lower figure in Fig. 1 shows how the probabilities of technology choice differ for each type of project participants. When the project participant type is E_Industrial, the probability of selecting Analytics software is remarkably high, and when the type of project participants is Energy company-centred, the IoT investment has a relatively high probability.
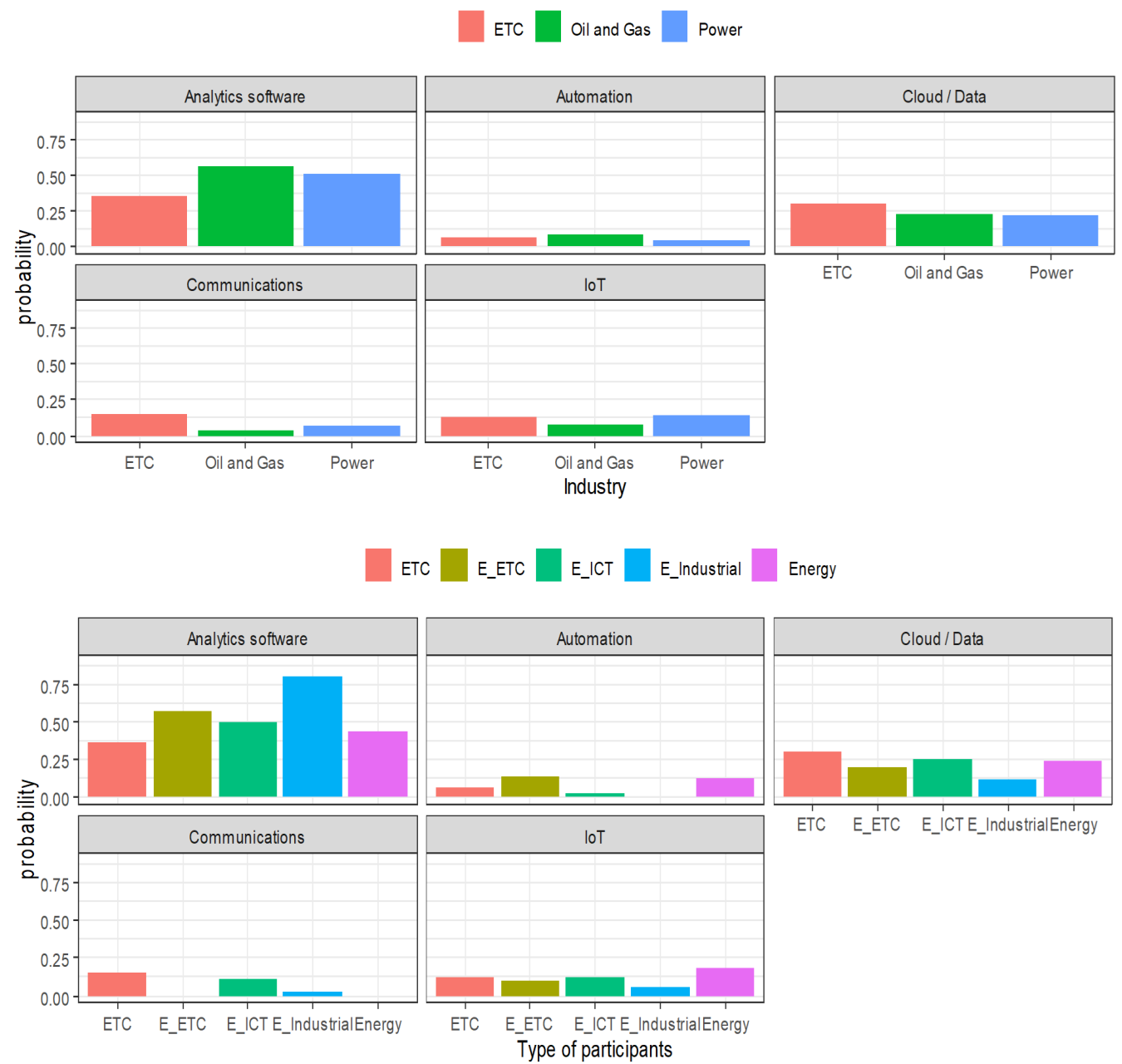

Fig. 1. Technology choice probability by industry and type of participants.

Fig. 2 shows the technology choice probability by type of participants in the power, oil and gas industry. In both the power, oil and gas industries, the participants type of Industrial has a stronger probability in Analytics software than other technologies. The difference between the power industry and the oil and gas industry is that the power industry has a relatively high probability value for the Energy company-centred form and E_ICT for the IoT investment. In the oil and gas industry, E_ETC participation takes a high proportion in Automation and ETC participation takes a high proportion in Cloud/Data. 


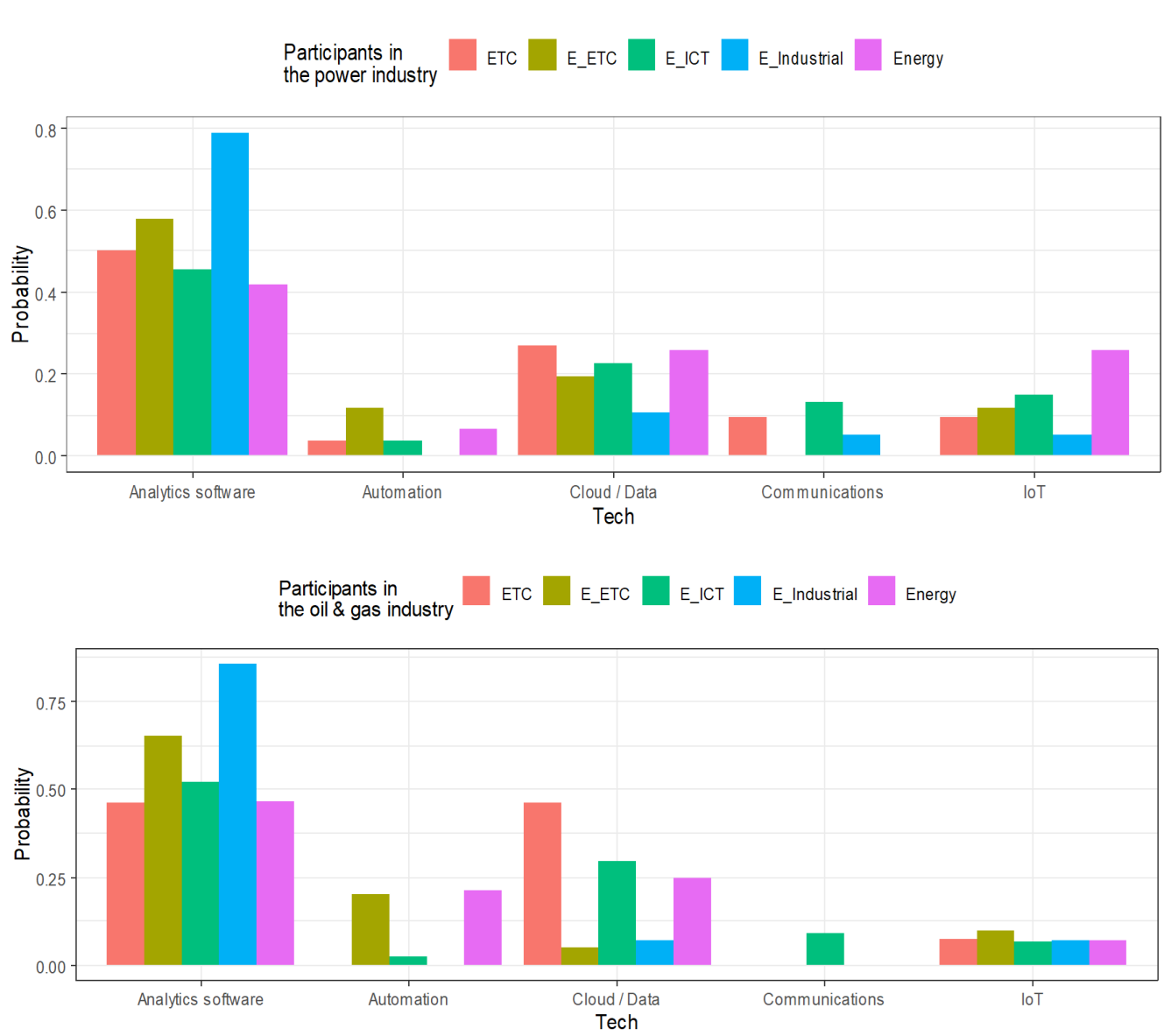

Fig. 2. Technology choice probability by type of participants in the power, oil and gas industry.

\section{DisCuSSION AND CONCLUSION}

As shown in upper figure in Fig. 1, the overall importance of Analytics software is high and the phenomenon intensifies in the energy sector. While the ETC sector has a generally similar probability of choice between Analytics software and Cloud/Data, the energy industry in the power, oil and gas sectors has a relatively high probability of choosing Analytics software. At this point, the demand for Analytics software such as predictive maintenance, industrial process optimization, and digital twin for energy production, storage, and delivery facilities in the energy sector is higher than in other industries. Analytics software is also available through traditional data management systems, but when cloud technology is combined, more people can take advantage of the benefits of Analytics software without any place constraints. Therefore, the amount of data is increasing in the energy sector, and it is expected to increase investment in Cloud/Data technology to enable many people to make data-based decisions.

Comparing the power, oil and gas sectors, although they are generally similar, the probability of investing in IoT is high in the power sector and Automation is high in the oil and gas sector. In the power industry, smart meters are being distributed actively, and as 
distributed resources are being distributed quickly, investment in IoT is increasing to efficiently manage sporadic distributed resources. In the oil and gas industry, Automation technologies such as drones and robots are actively utilized because production sites are usually located at remote distances.

The lower figure in Fig. 1 presented the probability of technology choice for each project participant. In the type of cooperation between energy companies and industrial companies, the probability of investing in Analytics software increases significantly. Analytics software basically utilizes the data that energy companies have, and it is interpreted that industrial companies, which have maintained close cooperation with energy companies, are significantly more likely to participate in Analytics software-related projects when they participate in digitalization projects. This aspect is also strongly evident in both sectors, even when looking at Fig. 2, which provide probability values of technology choice by project participant by power, oil and gas sector.

In the case of cooperation between energy companies and ICT companies, there is an even probability distribution in the power sector except Automation, and in the oil and gas sector, there is a strong tendency to focus on Analytics software and Cloud/Data. Cooperation between energy and ICT companies can be seen as more widespread in the power sector than in the oil and gas sector in terms of technology diversity. In Communications technology investments, energy companies are actively promoting cooperation with ICT companies due to the high entry barriers to establishing telecommunication networks.

Projects carried out alone or in cooperation between energy companies are likely to be in the order of Analytics software, IoT, Cloud/Data in the power sector, and in the oil and gas sector, the probability is high in the order of Analytics software, Cloud/Data, and Automation. When energy companies become the centre of investment, the IoT sector has relatively high probability values in power and the Automation sector in oil and gas. As mentioned earlier, this is largely due to differences in characteristics of the industry, and the more projects in which energy companies are the centre of investment, the more clearly reflect differences in characteristics of each industry.

Based on BNEF's Digitalization Leaderboard dataset, this study examines how technologies that focus on digitalization projects vary depending on the characteristics of digitalization projects. The data was short for about three years, and the pattern of change over time was not shown. However, at this point, it was possible to see what digital technologies were receiving attention depending on the project participant and the industry. However, it was not possible to verify which technologies are more likely to be invested as digitalization progresses, for example, whether there is an order of technologies invested. This study adds a variable called clean energy exposure to explore whether the higher the utilization of clean energy and smart energy technologies in the corporate financial structure, the more different the technology choice is. As mentioned in the previous results section, there were statistically significant differences in technology choice depending on the degree of clean energy exposure. However, this result alone cannot be determined that the higher the proportion of clean energy and the more digitalization progresses, the more likely it is to select a specific technology. It is necessary to perform further analysis using reliable analysis techniques after data is collected and built for a longer time in the future.

\section{REFERENCES}

[1] Park C., Heo W. Review of the changing electricity industry value chain in the ICT convergence era. Journal of Cleaner Production 2020:258:120743. https://doi.org/10.1016/j.jclepro.2020.120743 
[2] Brennen J. S., Kreiss D. Digitalization. The international encyclopedia of communication theory and philosophy 2016:1-11. https://doi.org/10.1002/9781118766804.wbiect111

[3] IEA. Smart Grid Technology Roadmap. Paris: International Energy Agency, 2011.

[4] Rehmani M. H., et al. Integrating renewable energy resources into the smart grid: Recent developments in information and communication technologies. IEEE Transactions on Industrial Informatics 2018:14(7):2814-2825. https://doi.org/10.1109/TII.2018.2819169

[5] Digital Transformation: Powering the Oil and Gas Industry. Oil \& Gas Journal 2018 [Online]. [Accessed 05.02.2021]. Available: https:/www.ogj.com/home/article/17297879/digital-transformation-powering-the-oil-gas-industry

[6] Park C., Kim H. The development structure and impact of information and communication convergence in the energy sector. Ulsan: Korea Energy Economics Institute, 2015.

[7] Yu H., Park K. Research on factors that utilize intelligent technology in the oil and gas sector. Ulsan: Korea Energy Economics Institute, 2017.

[8] Aveva. Digitalisation in Chemicals \& Petrochemicals. Paris: Aveva, 2018.

[9] Ghobakhloo M., Fathi M. Industry 4.0 and opportunities for energy sustainability. Journal of Cleaner Production 2021:295:126427. https://doi.org/10.1016/j.jclepro.2021.126427

[10] Ahmad T., Zhang D., Huang C., Zhang H., Dai N., Song Y., Chen H. Artificial intelligence in sustainable energy industry: Status Quo, challenges and opportunities. Journal of Cleaner Production 2021:289:125834. https://doi.org/10.1016/j.jclepro.2021.125834

[11] Jin H., Zhao J. Real-time energy consumption detection simulation of network node in internet of things based on artificial intelligence. Sustainable Energy Technologies and Assessments 2021:44:101004. https://doi.org/10.1016/j.seta.2021.101004

[12] BNEF. 2H 2020 Digital Trends in Power, Oil and Gas. New York, BNEF, 2021.

[13] Küfeoglu S., et al. Digitalisation and new business models in energy sector. Working paper, Faculty of Economics, University of Cambridge, 2019. https://doi.org/10.17863/CAM.41226

[14] Nambisan S., Wright M., Feldman M. The digital transformation of innovation and entrepreneurship: Progress, challenges and key themes. Research Policy 2019:48(8):103773. https://doi.org/10.1016/j.respol.2019.03.018

[15] Ahmad T., et al. Artificial Intelligence in Sustainable Energy Industry: Status Quo, Challenges and Opportunities. Journal of Cleaner Production 2021:289:125834. https://doi.org/10.1016/i.jclepro.2021.125834

[16] Coskun-Setirek A., Tanrikulu Z. Digital innovations-driven business model regeneration: A process model. Technology in Society 2021:64:101461. https://doi.org/10.1016/j.techsoc.2020.101461

[17] Swan M. Blockchain: Blueprint for a new economy. O'Reilly Media, Inc., 2015.

[18] Ferreira J. J., Fernandes C. I., Ferreira F. A. To be or not to be digital, that is the question: Firm innovation and performance. Journal of Business Research 2019:101:583-590. https://doi.org/10.1016/j.jbusres.2018.11.013

[19] Hess T., et al. Options for formulating a digital transformation strategy. MIS Quarterly Executive 2016:15(2):123-139.

[20] Monteiro F., Birkinshaw J. The external knowledge sourcing process in multinational corporations. Strategic Management Journal 2017:38(2):342-362. https://doi.org/10.1002/smj.2487

[21] Siachou E., Vrontis D., Trichina E. Can traditional organizations be digitally transformed by themselves? The moderating role of absorptive capacity and strategic interdependence. Journal of Business Research 2021:124:408 421. https://doi.org/10.1016/j.jbusres.2020.11.011

[22] Berggren C., Magnusson T., Sushandoyo D. Transition pathways revisited: established firms as multi-level actors in the heavy vehicle industry. Research Policy 2015:44(5):1017-1028. https://doi.org/10.1016/j.respol.2014.11.009

[23] Müller J. M. Antecedents to digital platform usage in Industry 4.0 by established manufacturers. Sustainability 2019:11(4):1121. https://doi.org/10.3390/su11041121

[24] Park C., Lee D. Analysis on new types of electric power businesses using a morphological box. Energy \& Environment 2021:32(1):113-133. https://doi.org/10.1177/0958305X20919413

[25] IEA. Digitalization and Energy. Paris, IEA, 2017.

[26] Mutlinomial Logistic Regression. R Data Analysis Examples [Online]. [Accessed 31.01.2021]. Available: https://stats.idre.ucla.edu/r/dae/multinomial-logistic-regression/

[27] Long J. S. Regression models for categorical and limited dependent variables (Vol. 7). Sage, 1997.

[28] Starkweather J., Moske A. K. Multinomial logistic regression. 2011 [Online]. [Accessed 31.01.2021]. Available: https://it.unt.edu/sites/default/files/mlr_jds_aug2011.pdf

[29] Interpreting $\exp (\mathrm{B})$ in multinomial logistic regression [Online]. [Accessed 03.02.2021]. Available: https://stats.stackexchange.com/questions/17196/interpreting-expb-in-multinomial-logistic-regression 